\title{
The Prevalence of Auto-Medication among Pregnant Women in a Conflict Affected, North West Region, Cameroon
}

\section{Tanyi Pride Bobga ${ }^{1,2 *}$, Sangwe Bertrand Ngwa $^{3}$, Ngwa Fabrice Ambe1,2,4, Ateh Stanislas Ketum ${ }^{5}$, Agbornkwai Nyenty Agbor ${ }^{5}$, Wirnkar Jude Kanla ${ }^{2,6}$, Mentoh Ajem Abungwi ${ }^{7}$}

\footnotetext{
${ }^{1}$ Model Preparatory Initiative of Academics, Research and Health, MOPIARH, Buea, Cameroon

${ }^{2}$ Modern United Faculties of Medicine Entrance Preparatory Center (MUFEPREC), Buea, Cameroon

${ }^{3}$ Centre Pasteur, Yaoundé, Cameroon

${ }^{4}$ Department of Medical Laboratory Sciences, INSAM Higher institute of Medical Sciences, Douala, Cameroon

${ }^{5}$ Family Health International, Yaoundé, Cameroon

${ }^{6}$ Department of Medical Laboratory Sciences, Faculty of Health Sciences, University of Buea, Buea, Cameroon

${ }^{7}$ Department of Pharmacy, Faculty of Medicine and Pharmaceutical Sciences, Douala, Cameroon

Email: ^bobgaatanyi@yahoo.com, ngwafabrice12@gmail.com, atehstanilask@gmail.com, ajemsamira@gmail.com, bertrandsangwe@yahoo.com,wirnkarjude1@gmail.com, a_nyenti@yahoo.com
}

How to cite this paper: Bobga, T.P., Ngwa, S.B., Ambe, N.F., Ketum, A.S., Agbor, A.N., Kanla, W.J. and Abungwi, M.A. (2021) The Prevalence of Auto-Medication among Pregnant Women in a Conflict Affected, North West Region, Cameroon. Journal of Biosciences and Medicines, 9, 122-137. https://doi.org/10.4236/jbm.2021.94010

Received: September 29, 2020

Accepted: April 18, 2021

Published: April 21, 2021

Copyright $\odot 2021$ by author(s) and Scientific Research Publishing Inc. This work is licensed under the Creative Commons Attribution International License (CC BY 4.0).

http://creativecommons.org/licenses/by/4.0/

(c) (i) Open Access

\begin{abstract}
Background: The excessive use of medicines and generally self-medication is considered as one of the major health and socio-economic problems in different countries. There is increasing evidence that self-medications among pregnant women are common in many developing countries. Despite the adverse impact on pregnancy, there are few programs available for their control. The Northwest region of Cameroon has been affected by socio-political crisis since 2016, which has slowed down economic activities and have grievous effects on the economy. It was therefore necessary to evaluate the prevalence of auto-medication amongst pregnant women. Aim: The aim of this study is to ascertain the knowledge, prevalence and practice of auto medication among pregnant women in Cameroon especially in the North West Region. Method: A community based cross-sectional study was conducted among 500 pregnant women, aged between 15 - 45 years in the Bamenda Health District between January to October 2019. A structured questionnaire based interview was used to collect data from each study subject. Then, data were categorized and analyzed using SPSS version 20 software. Results: The prevalence of auto-medication (allopathic and herbal medicines) in this study was 337 (67.4\%) and was predominant during the first trimester 246 (72.86\%) of pregnancy. 98 (29.09\%) previous experience, 70 (20.77\%) that they did not have money for consultation, 70 (20.77\%) non-severity of ailments and 75 (22.25\%) high cost of
\end{abstract}


medication in hospital/pharmacy were the most common reason pregnant women auto medicate. $96(28.48 \%)$ antiemetic, $72(21.36 \%)$ analgesics and 58 (17.21\%) antacids were the most frequent drugs used for auto-medication and the main symptoms for which pregnant women practice auto-medication were: $72(21.36 \%)$ fever/headache, 63 (18.69\%) constipation and 58 (17.21\%) nausea/vomiting. $116(34.42 \%)$ friends/family/neighbors were the main source of recommendation in auto medication. 96 (28.49\%) of the self-medicating pregnant women, self-medicate with local herbs and 40 (41.66\%) blood leaves (iron supplement) was the most used plant (herbs) in our study. Conclusion: We conclude that after 3 years of crisis in this region, the prevalence of auto-medication is increasing at a geometric rate and becoming a practical routine. Adequate counselling of reproductive age girls by healthcare professionals about the potential risks of self-medication with herbal medicine and allopathic drugs during pregnancy is strongly recommended.

\section{Keywords}

Pregnant Women, Bamenda Health District, Auto Medication, Allopathic Medicine, Herbal Medicine

\section{Introduction}

Nowadays, the excessive use of medicines and generally self-medication is considered as one of the major health and socio-economic problems in different countries [1]. Auto-medication is defined as the acquisition and use of one or more medicines without a physician's opinion or diagnosis as well as without prescription or therapeutic monitoring, including the use of herbal or allopathic medicines [2]. Auto medication is a global phenomenon that occurs in "people of all socio-demographic categories" [3]. In most developing countries such as Cameroon where there is ready accessibility to drugs, the likelihood that people will auto medicate is high, with the inclusion of pregnant women [4] [5]. The most common ailments for which the pregnant women practiced self-medication were the common cold, headache, anemia and nausea/vomiting [6]. There is a general fear among women in the use of allopathic or herbal medications during pregnancy. Some of the reasons for the increased rate of self-medication are the followings: the urge to self-care, feeling sympathy for the family members during illness, lack of health care services, poverty, ignorance, misconceptions, extensive advertisements on drugs and the availability of drugs in places other than pharmacies, high cost of consultation of private doctors, emergency use and prior experience about illness, ready access to drugs, greater availability of medicinal products [7]. Given the current global economic downturn and due to the difficulties to meet the health care needs of the people especially in sub-Saharan Africa, many countries are facing serious health challenges [8]. Such a condition in developing countries often motivates most of the people to practice self-medication using different types of materials and medical plants to meet their medical needs 
[9]. Nevertheless, many medicinal plants lack scientific evidence for their toxicity, chemical composition, and pharmacological effects. Despite improving access to healthcare in urban areas, many people rely on medicinal plants [6]. The World Health Organization pointed out that, auto medication could be good if properly done, because it helps to prevent and treat ailments that do not require medical consultation, provides the active role of the patient in his or her own health care [10]. Regardless of the unquestionable benefits obtained from auto medication, the negative effects of self-medication are diverse and may include effects such as treatment failures, drug toxicity, and increase in treatment cost, prolonged hospitalization periods and increase in morbidity. What makes self-medication more dangerous in developing countries is that the basic knowledge concerning the pharmacological properties of these drugs and how they may affect those who practice it are not well known [4] [5] [6]. The adverse effects of self-medication become more serious when the self-medicating person is a pregnant woman [4] [5] [6]. Self-medication by pregnant women especially in the first trimester of pregnancy can cause some serious effects to the unborn baby and the mother. These effects may include malformation of children, or hindrance in normal growth of the baby, defects in the development of the reproductive organs, urinary retention, intersex, undescended testis and other problems with the urethral [4]-[9].

In developing countries, and particularly in Africa, studies have revealed a higher burden $(30 \%-85 \%)$ of self-medication [11]. Studies reported in Ethiopia revealed a prevalence of auto medication among pregnant women of 50.4\% [12] and $69.4 \%$ [13], in Nigeria 85\% self-medication was reported among pregnant women [14], 59.9\% of pregnant women auto medicated in Democratic Republic of Congo [15] and prevalence of auto-medication with antimicrobials in Cameroon was $68.4 \%$ [16]. These figures suggest that prevalence of auto medication is high in many regions of the globe. The practice of auto-medication among pregnant women continues to be alarming, despite the associated risks. However, there is little documentary evidence on what has been done to ascertain the knowledge, prevalence and practice of auto medication among pregnant women in Cameroon especially in the North West Region.

\section{Materials and Methods}

\subsection{Study Area and Setting}

This study was carried out in the Bamenda Health District. Bamenda is the Capital City of the North West region, with an estimated population of about 2 million people and is located $366 \mathrm{~km}$ North West of Cameroon capital (Yaoundé). It is a town that offers educational, administrative purposes and farming to a large number of people from all the regions. A community based cross-sectional descriptive study was conducted among pregnant women in the Bamenda Health District (BHD). Briefly, the BHD is one of the 19 health districts in the North West region. It is located at the heart of the North West Regional Head 
Quarter (Bamenda) and has a population of over 500,000 inhabitants. It has 17 Health Areas-14 public and 3 confessionals. Bamenda has two major seasons-the dry season which is very dry and dusty and the cold rainy seasons.

\subsection{Study Design}

It was a community-based study. This study used a cross-sectional design to sample all pregnant women in the Bamenda Health District (BHD). The study period was between January 2019 to October 2019. The respondents (pregnant women) were given questionnaires designed in English, to assess the patterns of auto medication amongst pregnant women in a given place and time. Data were collected using standardized data collection instruments that were field-pretested to ensure reliability and validity.

\subsection{Study Population}

\subsubsection{Inclusion Criteria}

Pregnant women of all age group, resident in the Bamenda Health District who signed the Informed Consent form were included in the study.

\subsubsection{Exclusion Criteria}

All pregnant who were unable to communicate or hear and mentally disable were excluded from the study. Pregnant women who were absent during data collection and who did not sign the Informed Consent form were excluded from the study.

\subsection{Sampling Procedure}

The sampling method was a non-probability sampling (Consecutive), reason being that the researchers did not know the number of pregnant women that were present. However, this method relied on the researcher's ability to select pregnant women and the sampling technique was not a fixed or predefined selection process which made it difficult for all the participants (pregnant women) of the population to have equal opportunities to be included in the sample.

\subsection{Sample Size}

A sample size of 327 participants was calculated from the formula:

$$
N=\frac{Z^{2} \times P(1-P)}{d^{2}}
$$

where, $N=$ required sample size, $Z=$ confidence interval (95\%) i.e. 1.96, $P=$ pre-estimated prevalence $(69.4 \%)$ obtained from a similar study carried out by Jambo et al., in 2018 in Ethiopia [13] by. $d=$ error margin (5\%).

Sample size attained was 500 participants

\subsection{Ethical Considerations}

Administrative clearance was gotten from the North West regional delegation of 
public health and the Bamenda Health district. Participants were given a consent form respectively, to fill as an initial step in the participation process after the study purpose had been well explained to them. Participants were informed of their full autonomy over their participation in the study and the freedom to withdraw at any time if they so desired.

\subsection{Data Collection Tools}

Questionnaires were used in collecting quantitative data. The questionnaire was divided in to 4 sections, Section A; Socio-demographic data (age, sex, level of education, occupation, marital status), Section B; Prevalence of automedication (the number of people that took drugs without prescription), Section C; Knowledge of automedication (whether they were aware of the information about the drugs that they used and where they got the information) and Section D; Practice of auto medication (weather they took drugs without prescription, the number of times, the type of drug and the source of drug). The questionnaire was both an open ended and close ended questions.

\subsection{Data Management and Analysis}

Questionnaires were designed using Epi info version 7 and all data were entered into Microsoft Excel and analyzed using Statistical Package for the Social Sciences (SPSS) version 20 for windows. Data was collected using a questionnaire and checked for errors. Data were edited, coded and entered into a computer using Microsoft Excel software. Back up storage was done in $\mathrm{CD}$ and all raw data were stored safely in a computer secured with a password. After the data had been entered, univariate descriptive analysis, using frequency tables, Histograms, bar graphs and pie charts were derived. The analysis was guided by the key objectives and research questions and the analysis was done in relation to the literature reviewed.

\section{Results}

\subsection{Socio-Demographic Data}

\section{Distribution of Respondents According to Ages}

500 pregnant women patient aged range from 15 - 45 years were involved in this study. Majority 149 (29.8\%) of the participants falls within the age group $21-25$ years and age $(\geq 40)$ years constituted $34(6.80 \%)$ minority of the participants. Also the ages ranging from $15-20,26-30,31-35$ and $36-40$ years gave a total of $115(23.00 \%), 96(19.20 \%), 58(11.61 \%)$ and $48(9.60 \%)$ participants respectively (Table 1). Out of 500 participants, majority $264(52.88 \%)$ of the participant were married while minority $236(47.12 \%)$ of the participants were single. Among the 500 respondents who participated in this study, most $48.07 \%$ (240) of the participant has attained secondary level while minority $19.23 \%$ (96) of the participant was university student or graduates.

Based on the occupation of the study participants, majority $140(28 \%)$ of the 
Table 1. The demographic characteristics of pregnant women in the Bamenda Health District $(n=500)$.

\begin{tabular}{|c|c|c|}
\hline Variable & Frequency & Percentage (\%) \\
\hline \multicolumn{3}{|l|}{ Age (years) } \\
\hline $15-20$ & 115 & 23.0 \\
\hline $21-25$ & 149 & 29.8 \\
\hline $26-30$ & 96 & 19.2 \\
\hline $31-35$ & 58 & 11.61 \\
\hline $36-40$ & 48 & 9.60 \\
\hline$\geq 40$ & 34 & 6.8 \\
\hline \multicolumn{3}{|l|}{ Marital Status } \\
\hline Married & 264 & 52.88 \\
\hline Single & 236 & 47.12 \\
\hline \multicolumn{3}{|l|}{ Education } \\
\hline Primary & 164 & 32.7 \\
\hline Secondary & 240 & 48.07 \\
\hline University & 96 & 19.23 \\
\hline \multicolumn{3}{|l|}{ Occupation } \\
\hline Student & 87 & 17.4 \\
\hline Health personnel's & 42 & 8.4 \\
\hline Teacher & 36 & 7.2 \\
\hline Farmer & 140 & 28 \\
\hline Trader & 68 & 13.6 \\
\hline Civil servant & 58 & 11.6 \\
\hline Others & 69 & 13.8 \\
\hline
\end{tabular}

pregnant women were farmers while minority were teachers (Table 1). Also, based on occupations; student, civil servant, health personnel's, trader gave a total of $84(17.4 \%), 58(11.6 \%), 42(8.4 \%)$ and $68(13.6 \%)$ participants respectively while others $69(13.8 \%)$ which comprise of seamstress, hair dresser just to name a few.

\subsection{Evaluate the Prevalence of Auto Medication among Pregnant Women}

\subsubsection{Distribution of Respondents Based on If They Are Taking/Have} Taken Drugs without Prescription

A total of 500 participants were recruited for the study, 337 (67.4\%) respondents accepted that they are taking/have taken drugs without prescription while minority (32.6\%) 34 respondents refused taking automedication. Therefore the majority of the participants took drugs without prescriptions giving a prevalence of automedication (67.4\%) among pregnant women.

\subsubsection{Distribution of Respondents with Respect to the Stages of Pregnancy They Took Drugs without Prescription}

Out of the 337 respondents who accepted taking/have taken auto medication, $246(72.86 \%)$ confirmed taking drugs without prescription at 0 - 3 months of 
pregnancy, followed by $16(122.86 \%)$ at 4 - 6 months of pregnancy and $3(4.28 \%)$ at 7 - 9 months of pregnancy (Figure 1).

Out of the 337 participants who accepted taking/have taken auto medication, majority $96(28.48 \%)$ of the participants replied they recall taking antiemetic while minority $6(8.57 \%)$ took antimalarial drugs. Also, 72 (21.36\%), 58 (17.21\%) and $43(12.76 \%)$ of the 337 participants who accepted taking/have taken auto medication replied they took antacids, analgesics, and antibiotics respectively (Figure 2).

\subsubsection{Distribution of Respondents Based on How Often They Take Drugs without Prescription}

Out of the 337 participants who accepted taking/have taken auto medication,

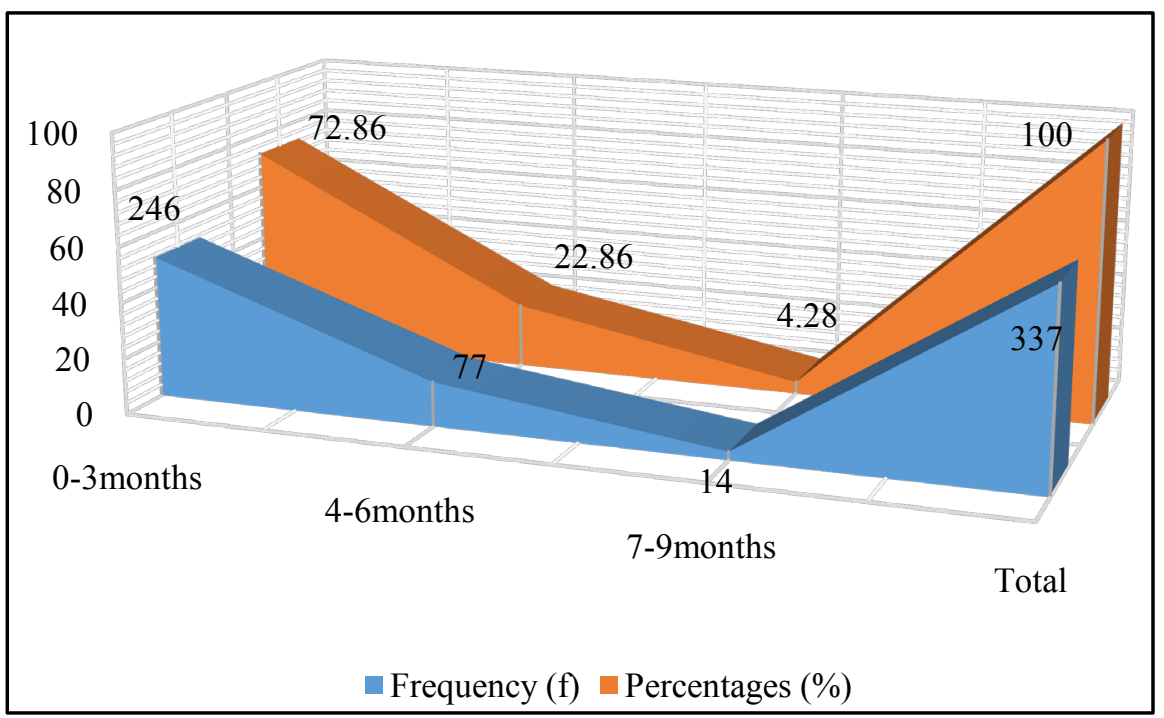

Figure 1. Distribution of respondent base on the stage of pregnancy they took auto medication.

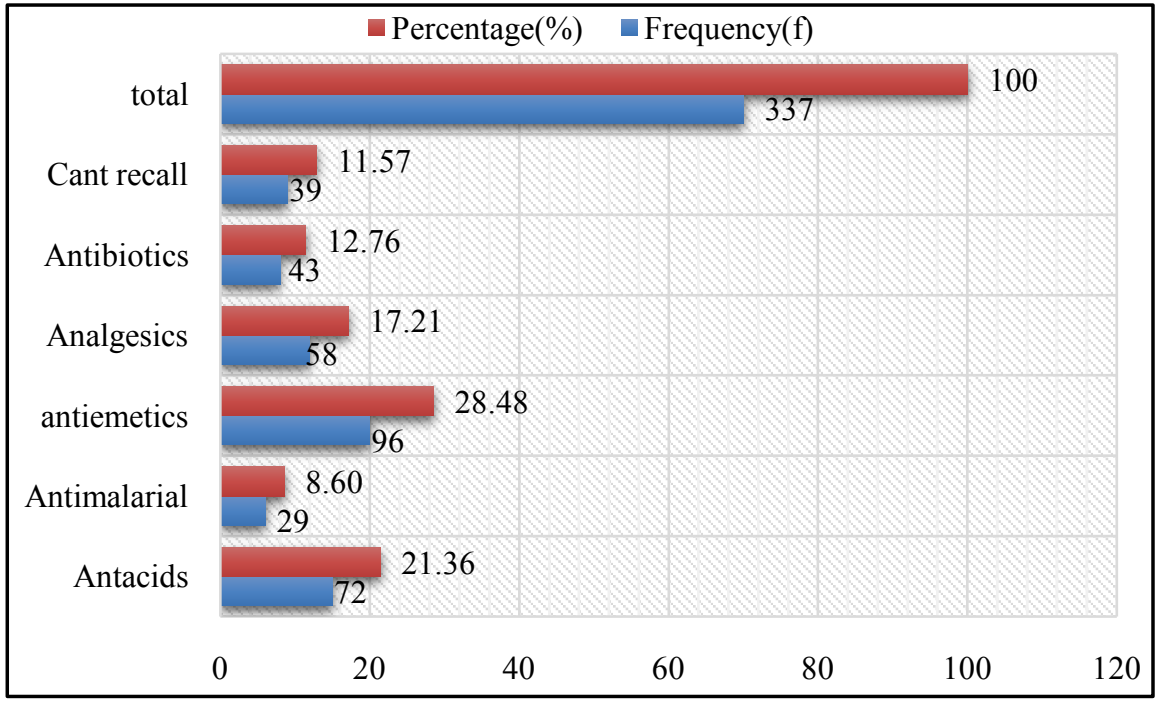

Figure 2. Distribution of respondents according to the drugs they recall taking. 
majority 130 (38.57\%) replied they have taken drugs without prescription twice while 38 (11.29\%) replied they cannot recall. Also, 63 (18.69\%) and $106(31.45 \%)$ of the 337 participants who accepted taking/have taken auto medication replied they have taken drugs without prescription once and often respectively (Figure 3).

\subsection{Evaluate the Knowledge of Auto Medication among Pregnant Women}

\subsubsection{Distribution of Respondents Based on Their Awareness on the Drugs Used}

Regarding the awareness on the drugs used, Out of the 337 participants who accepted taking/have taken auto medication, most $72(21.36 \%)$ respondents auto medicate because they had fever/headache while minority $43(12.76 \%)$ of the respondents could not recall while the auto medicate. 58 (17.21\%), 48 (14.24\%), 63 (18.69\%), 53 (15.73\%) of the 337 participants who accepted taking/have taken auto medication, auto medicate due to nausea/vomiting, cough/cold, constipation and gastritis respectively (Table 2 ).

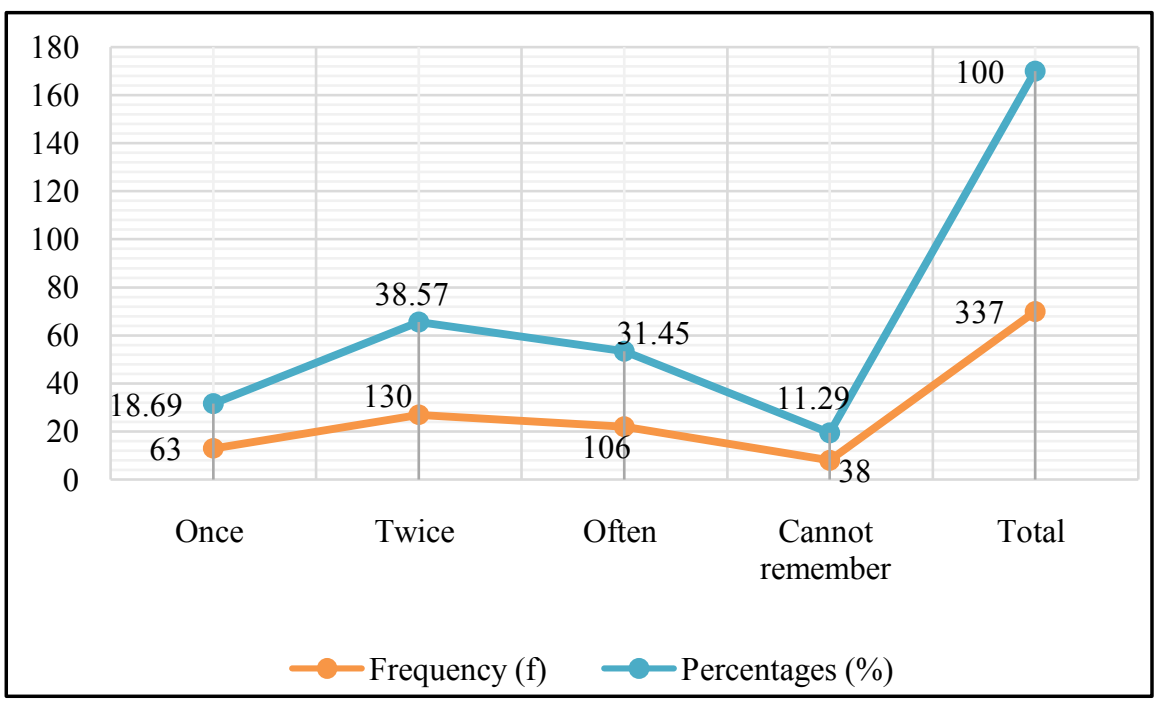

Figure 3. Distribution of respondent's base on how often they take auto medications.

Table 2. Distribution regarding the awareness on the drugs used.

\begin{tabular}{ccc}
\hline Responds & Frequency $(f)$ & Percentage (\%) \\
\hline Fever/headache & 72 & 21.36 \\
Cough/cold & 48 & 14.24 \\
Nausea/vomiting & 58 & 17.21 \\
Constipation & 63 & 18.69 \\
Gastritis & 53 & 15.73 \\
Cannot recall & 43 & 12.76 \\
Total & 337 & 100 \\
\hline
\end{tabular}




\subsubsection{Distribution of Participants Based on the Source of Information about these Drugs}

Out of the 337 participants who accepted to have taken drugs without prescription, majority 116 (34.42\%) of respondents who auto medicate replied that, their source of information was from friends/family/neighbours while minority 48 (14.24\%) replied was from hospital/pharmacy. 106 (31.45\%) and $67(19.88 \%)$ of the 337 participants who accepted to have taken drugs without prescription, replied that their source of information was from medicine stores and past prescription respectively (Figure 4).

\subsubsection{Distribution of Respondents If They Are Taking/Have Taken Herbal Medication}

Out of the 337 participants who accepted to have taken drugs without prescription, 96 (28.49\%) accepted talking herbal medications while 241 (71.51\%) refused taking herbal medications. Out of the 96 (28.49\%) respondents who accepted taking herbal medication, most $40(41.66 \%)$ respondents replied they took blood leaves (iron supplement) while minority $6(6.25 \%)$ of respondents said that they cannot recall. Also, 20 (20.83\%), 20 (20.83\%) and $10(10.41 \%)$ of the $96(28.49 \%)$ respondents who accepted taking/have taken herbal medication said they took masepo, fever grass and guava/pawpaw leaf respectively (Figure $5)$.

\subsection{Evaluate the Practice of Auto Medication among Pregnant Women}

\subsubsection{Distribution of Respondents Based on Their Reason for Getting Auto Medications}

Out of the 337 participants who accepted taking/have taken auto medications,

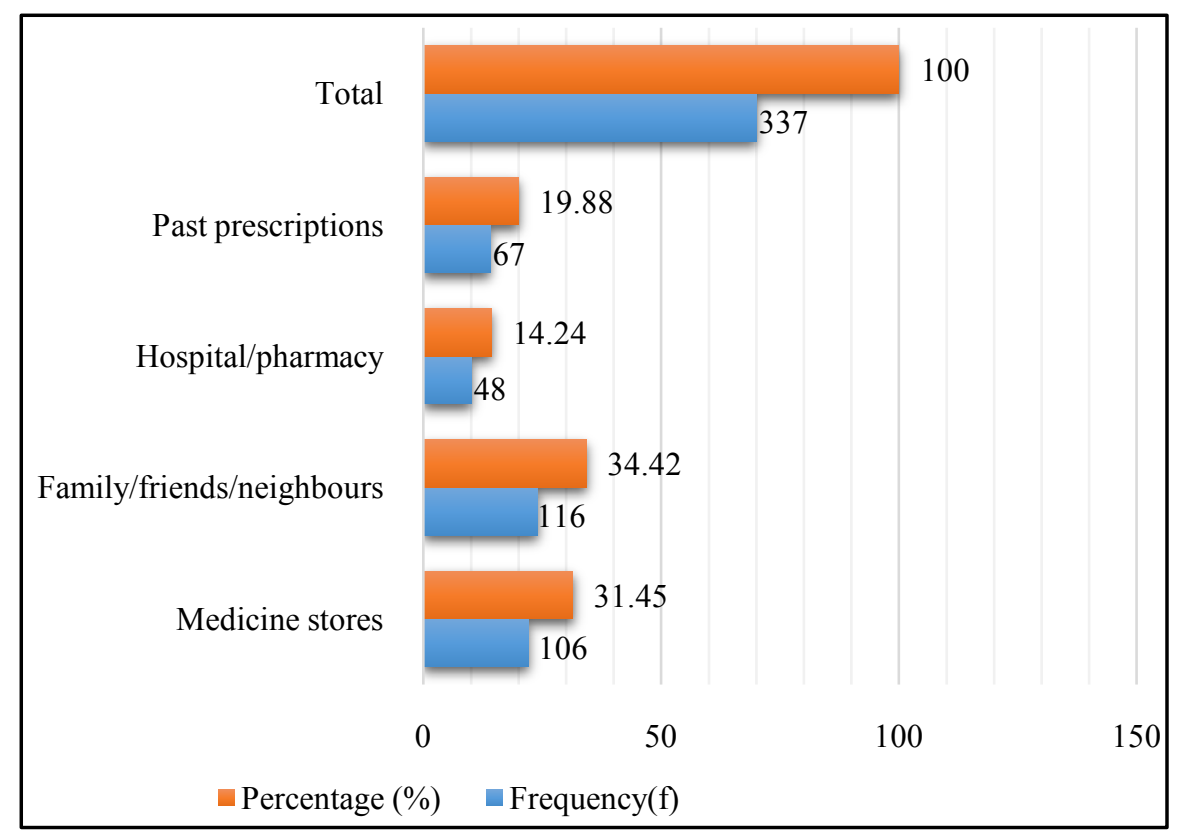

Figure 4. Distribution of respondents based on the source of information of the drugs. 


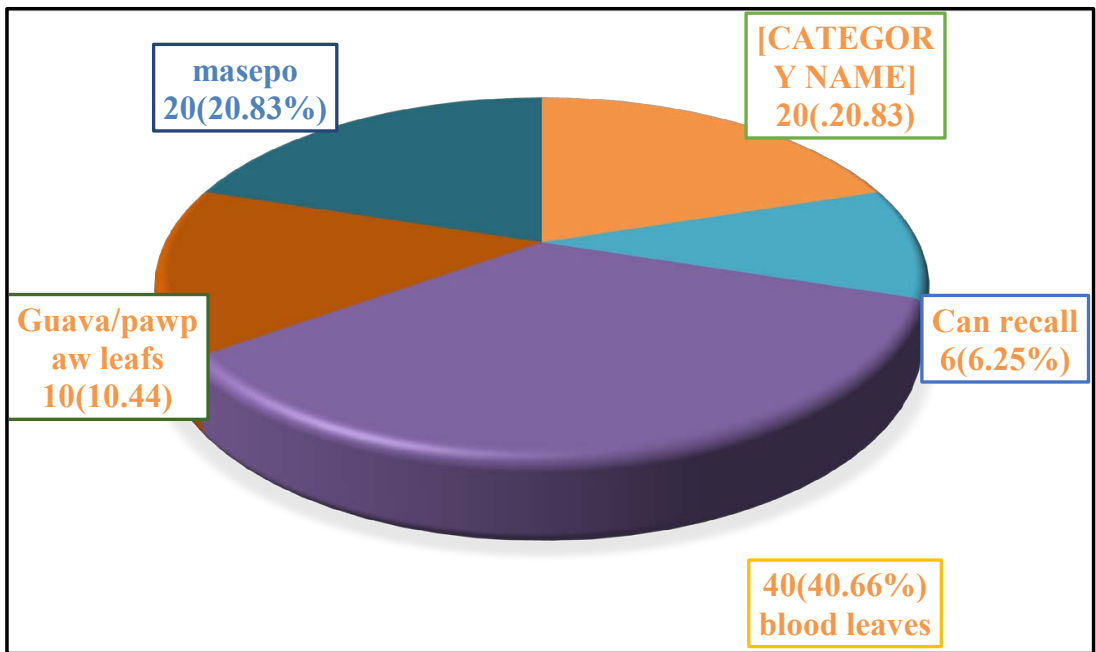

Figure 5. Distribution of respondents based on the herbal medication.

most $98(29.09 \%)$ said the auto medicate due to previous experience while minority $24(7.12 \%)$ auto medicate due to long distance from home to health facility. Also, 70 (20.77\%) 70 (20.77\%) and 75 (22.25\%), of the 337 participants who accepted taking/have taken auto medications, said the auto medicate because they did not have money for consultation, non severity of ailment and High cost of medication in hospital/pharmacy respectively (Table 3 ).

\subsubsection{Distribution of Respondents Based on the Outcome after Taking These Drugs}

Out of the 337 participants who accepted taking/have taken auto medications, majority 226 (67.06\%) of respondents replied they felt better after auto medication, followed by $63(18.69 \%)$ of respondents that, replied there was no changes and $48(14.25 \%)$ replied the situation get worse (Figure 6).

\subsubsection{Distribution of Respondents Who Think Auto Medication Is Preferred over Hospital Management of Mild Ailments}

Regarding respondents who think auto medication is preferred over hospital management of mild ailments, majority 217 (64.39\%) disagree that auto medication is preferred over hospital management of mild ailment while minority 120 (35.61\%) of respondents think that auto medication is preferred over hospital management of mild ailment. Out of the 120 (35.61\%) participants who think auto medication is preferred over hospital management of mild ailment and regarding their reasons, 38 (31.67\%) preferred auto medication because they easily felt relief while $24(20 \%)$ preferred auto medication because it's not time consuming and drugs are easily accessible respectively. Also, 34 (28.33\%) preferred to auto medicate because it is not expensive (Table 4).

\section{Discussion}

500 pregnant women, aged range from 15 - 45 years were involved in this study, majority 149 (29.8\%) of the participants were within the age range of $21-25$ yrs. 
Table 3. Distribution based on respondent reason why they auto-medicated.

\begin{tabular}{ccc}
\hline Responds & Frequency $(f)$ & Percentage (\%) \\
\hline High cost of medication in hospital/pharmacy & 75 & $22.25 \%$ \\
Previous experience & 98 & 29.09 \\
Non severity of ailment & 70 & 20.77 \\
Did not have money for consultation & 70 & 20.77 \\
Long distance from home to health facility & 24 & 7.12 \\
Total & 337 & 100.00 \\
\hline
\end{tabular}

Table 4. Respondent reasons think auto medication is preferred over hospital management of mild ailment.

\begin{tabular}{ccc}
\hline Responds & Frequency $(f)$ & Percentage $(\%)$ \\
\hline Not time consuming & 24 & 20 \\
Not expensive & 34 & 28.33 \\
They easily felt relief & 38 & 31.67 \\
Easy accessibility of drugs & 24 & 20 \\
Total & 120 & 100 \\
\hline
\end{tabular}

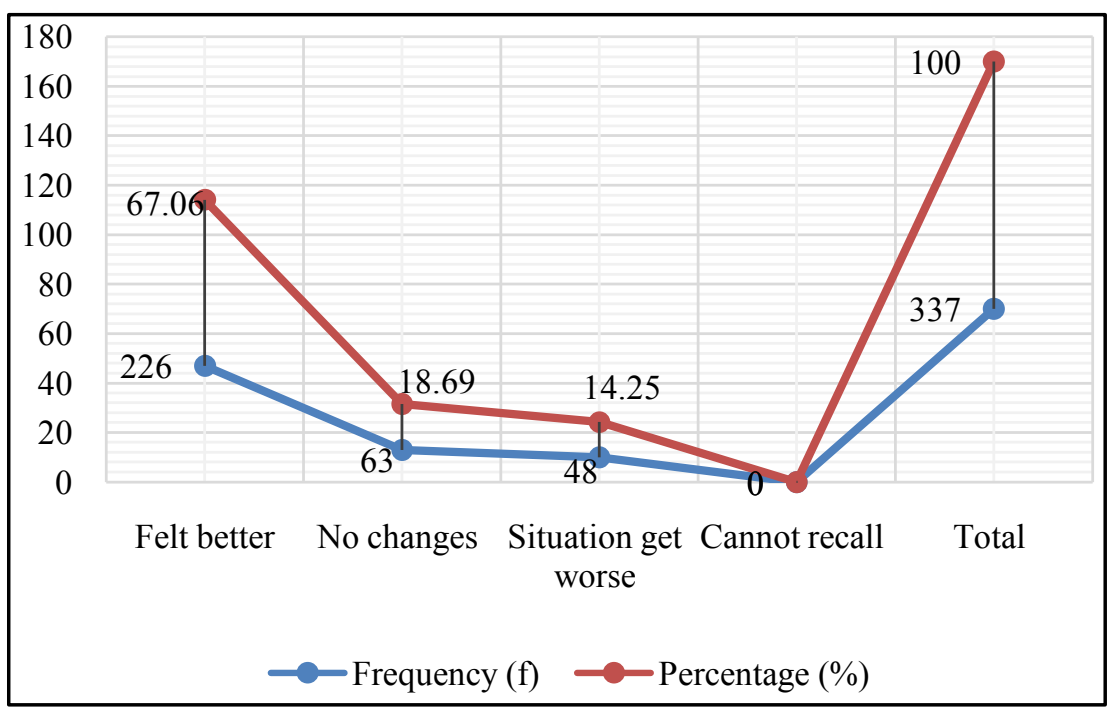

Figure 6. Distribution with regards on the outcome after auto medication.

This could be due to the fact that the practice of auto medication varies across ages, the younger the person is, the higher the tendency of auto medication. This finding is consistent with other studies [17] [18]. This can also be due to the fact that the women are in their active reproductive age. The results of the current study showed that, the prevalence of auto-medication among pregnant women is 337 (67.4\%); this result is in line with reports from other studies in Ethiopia [13] and Nigeria [4], where $69.4 \%$ and $72.4 \%$ were recorded respectively. The prevalence $(67.4 \%)$, recorded in this study is higher than reported by Alonso-Castro et 
al., 2018 [6] and Mohseni et al., 2018 [1], where prevalence of 21.9\% and 32\% were recorded respectively, these difference could probably be due to the fact that our study included both allopathic and herbal medicines for auto-medication but other studies included either of them .This research revealed that $48.07 \%$ of respondents had attained at least secondary education. This is in line to findings from Nigeria [4] and Ethiopia [13], which reported that majority of the pregnant women in their research had attained at least secondary education. The educational level of respondents is significant since some studies have suggested a link between education and the probability for self-medication. However, given the sensitivity and risks of auto-medication during pregnancy, $67.4 \%$ is a high rate and serious initiatives should be taken into account by authorities and health systems managers as well as families, in turn, in order to prevent and reduce the issues like fetal abnormalities wastage of resources, increased resistance of microbes, inaccurate self-diagnosis, failure to seek timely medical advice and other side effects in pregnancy due to auto-medication [19]. From our finding auto-medication was predominant during the first trimester 246 (72.86\%) of pregnancy, this result contrasts with the observation by Jambo et al., 2018 in Ethiopia [13], where self-medication was dominant during the third trimester of pregnancy. This could be due to the fact that during antenatal, pregnant women were educated by health practitioners on what medication to best consume and those that might cause harm to both her and fetus based on the various stages of pregnancy and in developing countries most pregnant women start antenatal during the second trimester of pregnancy. Based on the types of drug used, self-medication was classified self-medication with allopathic medicines and self-medication with herbal medicines. In this study; our finding reported that $96(28.48 \%)$ antiemetic, $72(21.36 \%)$ analgesics and $58(17.21 \%)$ antacids were the most frequent drugs used for auto-medication, this result is partly in line with reports by Yusuff et al., 2011 in Nigeria [20], where analgesics (paracetamol), vitamins and hematinics accounted for $68.1 \%$ of these medicines. This result is in contrary with reports from similar studies in Cameroon by Elvis et al., in 2019 [16], where auto-medication with antimicrobials gave a prevalence of $68.4 \%$. This difference could probably be due to the fact majority of respondents have knowledge of potential adverse effects of antibiotics to avoid during pregnancy. Prolonged use of analgesics (paracetamol) during pregnancy is associated to respiratory (asthma), neurological (hyperactivity, autism, among others) disorders in newborns [21] [22]. In this study, majority 226 (67.06\%) of respondents replied they felt better after auto medication, this result is contrary to report by Elvis et al., 2018, where the prevalence of hospitalization increases after self-medication. In this study, the main symptoms for which pregnant women practice auto-medication were: fever/headache, constipation and nausea/vomiting. This result is similar to studies carryout in Ethiopia [13] and Eastern DR Congo [15], where cold headache and nausea/vomiting were among the main symptoms for which the pregnant women practiced auto-medication. This result is contrary to report in the world [1], where the most important group of disease in which 
pregnant women self-medicated was anemia. These ailments are considered as minor ailments (fever/headache, constipation, anemia and nausea/vomiting) related to pregnancy and it is better to consult her doctor before proceeding to take any medications [6]. In this study, previous experience, they did not have money for consultation, non-severity of ailments and high cost of medication in hospit$\mathrm{al} /$ pharmacy was the most common reason pregnant women auto medicate. This result is in line with reports from other studies in the field of auto-medication [6]. Findings from our study revealed that 116 (34.42\%) friends/family/neighbours were the main source of recommendation in auto medication. This finding is in line with report from Turkey [23] and Ethiopia [13], where information provided by friends/family/ neighbours about the use of herbal medicine and/or conventional medicine may be insufficient to advise about potential toxic effects for the mother and child. Our findings show that 96 (28.49\%) of the 337 participants who accepted to have taken drugs without prescription, self-medicate with local herbs and this habit is generally rampant among Cameroonian and is consist with other studies [20]. This result is less than 58.2\% reported by Jambo et al., 2018 in Ethiopia [13], this difference is probably due to availability of herbs and cultural differences among study participants. Majority of our respondent that self-medicate do not take herbal medicine, this might be due the fear of harms to their fetus, considering it as an undesirable practice, lack of information about herbal medicine, fear of contaminations, mislabeling and there isn't a standardized dose for used. The most commonly used herbs in our study were 40 (41.66\%) blood leaves (iron supplement), 20 (20.83\%) masepo, 20 (20.83\%) fever grass and 10 (10.41\%) guava/pawpaw leaf. 40 (41.66\%). Blood leaves (iron supplement) was the most used herbs in our study, this could be due to the fact that during pregnancy, women suffer from shortage of blood (anemia) which is similar to a study carry out in Nigeria [4], where prevention of anemia was a call of consent.

\section{Conclusion}

Self-medication might increase maternal mortality and damage to fetus. This finding showed that self-medication is a common practice among pregnant women in our community and Cameroon at large. Adequate counselling of pregnant women by healthcare professionals about the potential risks of self-medication with herbal medicine and allopathic drugs during pregnancy is strongly warranted. In order to achieve the millennium development goal aimed at reducing child and maternal mortality, there is need to upgrade healthcare facilities and embark on regular massive enlightenment campaigns, especially in rural areas to encourage increased healthcare services utilization. In addition, healthcare providers, especially those that are involved in antenatal care should be aware of evidence regarding potential benefits or harm of herbal and conventional medicine when used by pregnant women. There is a need for education of the public on the danger of self-medication and the potential harmful effect on the unborn child. This will ensure attitudinal change and encourage safer practice. 


\section{What Is Already Known on This Topic?}

- Today, self-medication is now one of the greatest health's, economic and social problems in different societies, including Cameroon;

- Auto-medication during pregnancy is associated with adverse effects and lack of knowledge and little information of mothers about use of drugs, could be harmful for the family and society.

\section{What This Study Adds}

- Adequate education of pregnant women during antenatal care on the potential danger of auto medication is necessary;

- There is a high prevalence of auto-medication among pregnant women.

\section{Authors' Contributions}

TPB and NFA conceived and designed the study; TPB, ASK, MAA, SBN and NFA conducted the study; WJK, NCT, ZBF, ANA and NFA performed data analysis and interpretation; TPB, and NFA wrote the first draft of the manuscript and ANA, WJK, ASK, ANA, SBN reviewed and corrected the manuscript. SBN, TPB, WJK constituted the questionnaire for the study. SBN, NFA, ANA, MAA did proofreading and inputting of data into Excel sheet. All authors approved the final copy.

\section{Funding}

No external funding was gotten for this work.

\section{Acknowledgements}

We are grateful to all pregnant women who participated in this research.

\section{Conflicts of Interest}

The authors declare no competing interest.

\section{References}

[1] Mohseni, M., Azami-Aghdash, S., Gareh Sheyklo, S., Moosavi, A., Nakhaee, M., Pournaghi-Azar, F. and Rezapour, A. (2018) Prevalence and Reasons of Self-Medication in Pregnant Women: A Systematic Review and Meta-Analysis. IJCBNM, 6, 272-284.

[2] World Health Organiztion [WHO] (2018) The Role of the Pharmacist in Self-Care and Self-Medication, 1998.

http://apps.who.int/medicinedocs/pdf/whozip32e/whozip32e.pdf

[3] Shafie, M., Eyasu, M., Muzeyin, K., Worku, Y. and MartôÂn-AragoÂn, S. (2018) Prevalence and Determinants of Self-Medication Practice among Selected Households in Addis Ababa Community. PLoS ONE, 13, e0194122.

https://doi.org/10.1371/journal.pone.0194122

[4] Abasuibong, F., Bassey, E.A., Udobong, J.A., Akinbami, S.O., Udoh, S.B. and Idung, A.U. (2012) Self-Medication: Potential Risk and Hazard among Pregnant Women in Uyo, Nigeria. Pan African Medical Journal, 13, 15. 
[5] Joseph, B., Ezie, I., Aya, B. and Dapar, M. (2017) Self-Medication among Pregnant Women Attending Ante-Natal Clinics in Jos-North, Nigeria. IJTDH, 21, 1-7. https://doi.org/10.9734/IJTDH/2017/28248

[6] Alonso-Castro, A.J., Ruiz-Padilla, A.J., Ruiz-Noa, Y., Alba-Betancourt, C., Domínguez, F., Ibarra-Reynoso, L.D.R., Maldonado-Miranda, J.J., Carranza-Álvarez, C., Blanco-Sandate, C., Ramírez-Morales, M.A., Zapata-Morales, J., Deveze-Álvarez, M.A., Mendoza-Macías, C.L., Solorio-Alvarado, C.R. and Rangel-Velázquez, J.E. (2018) Self-Medication Practice in Pregnant Women from Central Mexico. Saudi Pharmaceutical Journal, 26, 886-890. https://doi.org/10.1016/j.jsps.2018.03.008

[7] Ahmad, A., Patel, I., Mohanta, G.P. and Balkrishnan, R. (2014) Evaluation of Self-Medication Practices in Rural Area of Town Sahaswan at Northern India. Annals of Medical and Health Sciences Research, 4, S73-S78. https://doi.org/10.4103/2141-9248.138012

[8] Bagheri, A. and Abbaszadeh, F. (2014) Self-Medication and Supplement Use by Pregnant Women in Kashan Rural and Urban Areas. Journal of Mazandaran University of Medical Sciences (JMUMS), 24, 151-157.

[9] Befekadu, A., Dhekama, N.H. and Mohammed, M.A. (2014) Self-Medication and Contributing Factors among Pregnant Women Attending Antenatal Care in Ethiopia: The Case of Jimma University Specialized Hospital. Medicine Science, 3, 969-981. https://doi.org/10.5455/medscience.2013.02.8098

[10] World Self-Medication Industry (WSMI) (2010) The Story of Self-Care and Self-Medication: 40 Years of Progress, 1970-2010. Ferney-Voltaire.

[11] Elong Ekambi, G.-A., Okalla, E.C., Penda, I.C., Nnanga Nga, E., Mpondo, M.E. and Eboumbou, M.C.E. (2019) Knowledge, Practices and Attitudes on Antibiotics Use in Cameroon: Self Medication and Prescription Survey among Children, Adolescents and Adults in Private Pharmacies. PLoS ONE, 14, e0212875. https://doi.org/10.1371/journal.pone.0212875

[12] Bayisa, B., Tatiparthi, R. and Mulisa, E. (2014) Use of Herbal Medicine among Pregnant Women on Antenatal Care at Nekemte Hospital, Western Ethiopia. Jundishapur Journal of Natural Pharmaceutical Products, 9, e17368. https://doi.org/10.17795/jjnpp-17368

[13] Jambo, A., Mengistu, G., Sisay, M., Amare, F. and Edessa, D. (2018) Self-Medication and Contributing Factors among Pregnant Women Attending Antenatal Care at Public Hospitals of Harar Town, Ethiopia. Frontiers in Pharmacology, 9, 1063. https://doi.org/10.3389/fphar.2018.01063

[14] Emmanuel, A., Achema, G., Afoi, B.B. and Maroof, R. (2014) Self Medication Practice among Pregnant Women Attending Antenatal Clinic in Selected Hospitals in Jos, Nigeria. International Journal of Nursing and Health Science, 1, 55-59.

[15] Mbarambara, P.M., Songa, P.B., Wansubi, L.M., Mututa, P.M., Minga, B.B.K. and Bisangamo, C.K. (2016) Self-Medication Practice among Pregnant Women Attending Antenatal Care at Health Centers in Bukavu, Eastern DR Congo. International Journal of Innovation and Applied Studies, 16, 38-45.

[16] Amin, E.T., Charles, N., Fondugallah, J.A., Fualefac, A. and Njunkeng, P.A. (2019) Prevalence of Antimicrobial Self-Medication among Patients Attending Two Hospitals in the Buea Health District, Cameroon. Archives of Community Medicine and Public Health, 5, 24-28. https://doi.org/10.17352/2455-5479.000048

[17] Kulkarni, P.K., Khan, M. and Chandrasekhar, A. (2012) Self-Medication Practices among Urban Slum Dwellers in South Indian City. International Journal of Pharma and Bio Sciences, 3, 81-87. 
[18] Baig, S. (2012) Self-Medication Practices. The Professional Medical Journal, 19, 513-521.

[19] Ebrahimi, H., Atashsokhan, G., Amanpour, F. and Hamidzadeh, A. (2017) SelfMedication and Its Risk Factors among Women before and during Pregnancy. Pan African Medical Journal, 27, 183. https://doi.org/10.11604/pamj.2017.27.183.10030

[20] Yusuff, K.B. and Omarusehe, L.D. (2011) Determinants of Self-Medication Practices among Pregnant Women in Ibadan, Nigeria. International Journal of Clinical Pharmacy, 33, 868-875. https://doi.org/10.1007/s11096-011-9556-4

[21] Toda, K. (2017) Is Acetaminophen Safe in Pregnancy? Scandinavian Journal of Pain, 17, 335-446. https://doi.org/10.1016/j.sjpain.2017.09.007

[22] Bremer, L., Goletzke, J., Wiessner, C., Pagenkemper, M., Gehbauer, H.B., Tolosa, E., Hecher, K., et al. (2017) Paracetamol Medication during Pregnancy: Insight on Intake, Frequencies, Dosage and Effects on Hematopoetic Stem Cell Population in Cord Blood from a Longitudinal Prospective Pregnancy Cohort. EbioMedicine, 26, 146-151. https://doi.org/10.1016/j.ebiom.2017.10.023

[23] Kissal, A., Cevik, G.U. and Batkin, E.D. (2017) Use of Herbal Product among Pregnant Women in Turkey. Complementary Therapies in Medicine, 30, 54-60.

https://doi.org/10.1016/j.ctim.2016.11.001

\section{List of Abbreviations}

BHD: Bamenda Health District. 